\title{
Intravenous Hypnotic Regimens in Patients With Liver Disease; A Review Article
}

\author{
Hassan Soleimanpour ${ }^{1}$; Saeid Safari ${ }^{2}$; Farzad Rahmani ${ }^{3}$; Asghar Jafari Rouhi ${ }^{4}$; Seyed \\ Moayed Alavian ${ }^{5,}$ \\ ${ }^{1}$ Cardiovascular Research Center, Tabriz University of Medical Sciences, Tabriz, Iran \\ ${ }^{2}$ Department of Anesthesiology, Iran University of Medical Sciences, Tehran, Iran \\ ${ }^{3}$ Road Traffic Injury Research Center, Tabriz University of Medical Sciences, Tabriz, Iran \\ 4 4tudents' Research Committee, Tabriz University of Medical Sciences, \\ 5 Baqiyatallah Research Center for Gastroenterology and Liver Diseases, Baqiyatallah University of Medical Sciences, Tehran, Iran \\ *Corresponding author: Seyed Moayed Alavian, Baqiyatallah Research Center for Gastroenterology and Liver Diseases, Baqiyatallah University of Medical Sciences, Tehran, IR Iran. \\ Tel/Fax:+98-81262072, E-mail: Alavian@thc.ir
}

Received: September 27, 2014; Revised: December 11, 2014; Accepted: December 18, 2014

\begin{abstract}
Context: The liver as an important organ in the body has many essential functions in physiological processes. One of the major activities of liver is drug metabolism. Hepatic dysfunction affecting hepatic physiological activities, especially drug metabolism can cause many problems during anesthesia and administration of different drugs to patients.

Evidence Acquisition: Studies on hepatic disorders and hypnotic anesthetics prescribed in hepatic disorders were included in this review. For this purpose, reliable databases were used.

Results: Anesthesia should be performed with caution in patients with hepatic dysfunction and drugs with long half-life should be avoided in these patients.

Conclusions: A review of the literature on the use of hypnotic drugs in patients with liver dysfunction showed that some hypnotic drugs used during anesthesia could be safely used in patients with impaired liver function. In these patients, certain drugs should be used with caution.
\end{abstract}

Keywords:Liver Disease; Anesthesia; Hypnotics Drugs

\section{Context}

The liver plays an important role in the physiology of body, such as food and drug metabolism, production of plasma proteins and hemostatic factors, detoxification and elimination of endogenous and exogenous substances $(1,2)$. Extent of surgery in patients with cirrhosis and chronic liver disease is increasing every day (3).

Liver disease is classified into acute and chronic types; the most common causes of acute type in the world are viral infections, alcohol and drug toxicity (A very common cause in developed countries, so that $70 \%$ of patients in the UK are related to acetaminophen toxicity)(4). Viral hepatitis types B and C, alcohol consumption, autoimmune hepatitis and genetic disorders are some major and common causes of chronic liver dysfunction (5).

It could be due to increased survival and improved postoperative outcomes in these patients (6). Anesthesia in a patient with liver disease is a controversial condition, even for experienced anesthesiologists (7).

Anesthesia reduces mean arterial blood flow in the liver and the amount of oxygen to the liver and it does not cause a problem in healthy people. A mild increase in liver enzymes, alkaline phosphatase and bilirubin are commonly seen in surgical procedures, which the situation is seen in general anesthesia and local and spinal anesthesia (8). However, there is a transient increase in liver enzymes and it does not cause adverse effects in people with normal liver function, but in patients with liver disease results in hepatic impairment (9). It has been shown that cardiac surgery mortality rate is high in patients with liver cirrhosis (10).

Recent developments have led to some improvements in surgery and anesthesia and the results for hepatic patients who undergo anesthesia and surgery (7-11). In addition, patients with liver dysfunction have a high risk of morbidity and mortality after anesthesia and surgery (12). Pre-anesthesia and postoperative care to reduce morbidity and mortality of patients with hepatic impairment is of particular importance. The use of intravenous anesthetic drugs, for systemic use in both patients with normal liver function and those with liver disorders, is associated with complications. Choice of anesthetic agent should be based on variables such as proteins bonded to drug, drug metabolism and drug half-life (3-13). Therefore, to choose the right medication in this case, proper-

Copyright (C) 2015, Iranian Society of Regional Anesthesia and Pain Medicine(ISRAPM). This is an open-access article distributed under the terms of the Creative Commons Attribution-NonCommercial 4.0 International License (http://creativecommons.org/licenses/by-nc/4.0/) which permits copy and redistribute the material just in noncommercial usages, provided the original work is properly cited. 
ties, metabolism and adverse effects, particularly liver complications of anesthetic and sedative drugs, should be studied. To achieve this goal, we decided to look at relevant articles in reliable databases.

\section{Evidence Acquisition}

To find the required articles, the best available evidence regarding the use of hypnotic anesthetic agents in liver diseases was used. First, a literature search of systematic reviews, randomized clinical trials and evidence-based medical guidelines was performed and reliable databases were used. Search was performed based on keywords including anesthesia, liver dysfunction, hypnotic anesthetics and general anesthesia in patients with hepatic diseases, hypnotic anesthetics complications and similar words. In this article, only articles published since 1965 were examined and the inclusion and exclusion criteria were as follows:

Inclusion criteria:

1) Articles that examined the impact and use of hypnotic anesthetic drugs in liver diseases

2) Articles performed in adults.

Exclusion criterion: Articles not published in English.

\section{Results}

\subsection{Overview of anesthesia in hepatic disease}

In recent years, a significant increase has been occurred in the number of patients with impaired hepatic function or end stage liver disease requiring surgery. In evaluating these patients, anesthesiologists should have sufficient knowledge of the underlying disease and its impact on the performance of other organs, the risks of anesthesia and anesthetic effect on the underlying disease as well. In preoperative evaluation of these patients, probability of hepatic encephalopathy, pleural effusion, cardiomyopathy in cirrhosis and coagulation disorders should be considered. Using the Child-Turcotte-Pugh and the model for end stage liver disease scores can help anesthesiologists determine the risk of surgery (14). When inducing anesthesia in patients with hepatic disease, close monitoring should be performed for the patient. Thus, oxygen demand and supply should be carefully monitored, which is achieved through precise control of pulmonary ventilation and cardiovascular function. Therefore, intravascular volume, cardiac output and tissue perfusion pressure should be in the normal range (7).

Volatile anesthetics, narcotics and intravenous anesthetics are well tolerated in liver insufficient patients under control, but caution should be taken in decompensated patients, as long-standing effect of drugs, effects on hemodynamics and subsequent encephalopathy make it difficult to control anesthesia and prolonged impairment of consciousness after anesthesia $(7,11,13)$. If possible, local anesthesia is performed in patients with advanced hepatic diseases. However, it is not allowed in patients with coagulopathy diseases $(7,15)$.

Opioids are successfully used in patients with liver diseases and in the meantime fentanyl is the drug of choice for these patients when using with average dosage, the oxygen content of the liver and liver blood flow are not affected $(14,16)$.

Among the drugs used for anesthesia induction, propofol is the drug of choice in patients with liver diseases (17). As a rule, any type of long-acting anesthetic agent should not be used in patients with cirrhosis. Fentanyl from narcotics, lorazepam and oxazepam from sedatives, along with some anesthetic gases such as Sevoflurane or intravenous anesthetics such as propofol, are recommended in these patients (18-20).

\subsection{Hypnotic Agents}

\subsubsection{Barbiturates}

Barbiturates, especially thiopental are traditional anesthetic agents used in the operating room and to a lesser extent in the emergency department. The drug rapidly crosses the blood brain barrier and induces anesthesia in less than a minute and then rapidly absorbed and metabolized in the liver (21). Using a single dosage of thiopental intravenously induces anesthesia for 5 to 10 minutes; this time is 4 to 6 minutes for methohexital (22, 23). Barbiturates advantages include high strength, rapid onset, short duration, a decrease in brain metabolism, reduction in oxygen consumption and a reduction of cerebral blood flow and Intracranial Pressure (ICP) $(24,25)$. Using barbiturates in hypovolemic patients leads to hypotension and disruption of cerebral perfusion pressure (CPP). The considerable adverse effect of barbiturates is vasomotor center depression and decreased myocardial contractility, which can lead to hypotension and it has been shown that a decrease to an average of $40 \mathrm{~mm} \mathrm{Hg}$ in Mean Arterial Pressure (MAP) occurs (26).

Although barbiturates do not affect the hepatic blood flow, the drug may underlie the development of hepatic encephalopathy by binding to Gamma Amino Butyric Acid (GABA) receptors in the brain; therefore, the drug should be used with caution in patients with liver diseases (8). Thiopental metabolism in patients with cirrhosis is reduced, on the other hand, proteins attached to thiopental are also reduced, and thus, the overall clearance of the drug does not change in patients with cirrhosis (27). This medication should not be used in patients with hepatic impairment and if used the dosage should be reduced $(17,28)$. Other adverse effects of the drug include cough, sneezing and hiccups (29). A case of jaundice and hepatitis was reported following the use of thiopental by Hasselstrom in 1979 (29).

\subsubsection{Etomidate}

Etomidate is a water-soluble and fat-soluble carboxylated imidazole anesthetic agent $(21,31)$. The drug is rap- 
idly hydrolyzed in plasma and liver and excreted in the urine (32). The important advantage of etomidate is the lack of cardiac depression effect $(30,31)$. Due to the lack of analgesic effects, the drug should be used with painkiller $(21,32)$. The most important feature of etomidate in emergency department is the hemodynamically stability with no changes in MAP (33-35). However, slight increase in Heart Rate (HR) occurs (36). Most common adverse effects of etomidate include injection site pain, nausea and vomiting and myoclonic muscle jump $(29,37)$. Other adverse effects of the drug include hypo and hyperventilation, apnea (5 to 90 seconds), tachycardia and bradycardia (29). The amount of clearance of etomidate in patients with cirrhosis is similar to that of normal patients. However, the distribution volume of the drug in patients with liver cirrhosis is doubled (38).

\subsubsection{Ketamine}

Ketamine is an anesthetic agent, which gives a dissociative anesthesia, along with analgesia and amnesia while the patient is awake. The medication is used to treat patients severely agitated and with resistant delirium (21). Ketamine is a water and fat soluble drug and easily enters the central nervous system (CNS), and like barbiturates rapidly accumulated and metabolized in the liver (21). The drug adverse effects include increased blood pressure, increased heart rate and cardiac output, diplopia, nistagmus, increased intraocular pressure, nausea, vomiting and anorexia (30). Chronic abuse of ketamine can cause liver fibrosis, common bile duct (CBD) dilatation and microscopic damage to CBD (38-40). In patients receiving Ketamine for infusion chronic pain, several cases of ketamine-related injuries have been reported, as an increase in liver enzymes (approximately 3-fold higher) and takes about three months (41). Due to good analgesia, ketamine is used in patients undergoing colonoscopy, as in the study conducted by Khajavi et al. on 60 patients undergoing colonoscopy sedated with a combination of propofol and ketamine, patient satisfaction was significantly higher compared to those sedated by a combination of propofol and fentanyl (42).

\subsubsection{Propofol}

Propofol is an anesthetic widely used in emergency department. The drug has alkylphenol composition. Analgesic effects of the drug are slight, but it has amnestic effects $(43,44)$. Propofol is a lipophilic and water-insoluble drug, which is rapidly absorbed by (brain) tissue and quickly spread in fat and muscle and finally metabolized by the liver and excreted through the kidneys (45). Propofol is often successfully used in children and adults with refractory status epilepticus (46). In a study by Soleimanpour et al. on 90 patients with migraine headaches, it was shown that propofol is an effective and safe treatment in these patients (47). Because the drug has a high affinity for GABA receptors and altered and activated physiologi- cal characteristics of the receptor, it reduces pain (48). It lowers MAP (10 $\mathrm{mmHg}$ ), thus reducing blood flow to the brain. Other adverse effects include acidosis (metabolic and respiratory), rashes, hives, decreased IOP, injection site pain, seizure-like dystonic movements, nausea, abnormal taste of mouth felt immediately after injection and acute pancreatitis (29). Propofol infusion syndrome is a rare complication of continuous infusion of propofol when used for more than 48 hours with dose higher than $4 \mathrm{mg} / \mathrm{kg} / \mathrm{h}$. The pathophysiology of the complication is unknown, but impaired mitochondrial respiratory chain is involved in creation of syndrome (49). The complication is characterized by metabolic acidosis, rhabdomyolysis of skeletal muscle and cardiac muscle, arrhythmias (bradycardia, atrial fibrillation, supraventricular and ventricular tachycardia, bundle branch block and asystole), heart failure, renal failure, hepatomegaly and death. Continuous propofol infusion syndrome includes extra hepatic and intrahepatic complications. Hepatic complications of the syndrome including hepatomegaly and fatty liver are because of the high fat content of drug $(49,50)$.

Rison and Ko reported a few cases of fatty liver induced by propofol infusion in children with status epilepticus, in which cases had no extra hepatic complications (46). In many texts, propofol has been suggested as the drug of choice for anesthesia in patients with cirrhosis (1720). In a study conducted by Faga et al. on 240 cases of colonoscopy and ERCP sedated by propofol, it was shown that performing the procedure under sedation by propofol had no complications on patients with and without cirrhosis (51). The incidence of hepatic encephalopathy caused by endoscopy has not been reported with sedation by propofol in patients with cirrhosis $(52,53)$. Asai and Yagi described a case of liver injury induced by repeated injections of propofol in a patient with psychiatric disease treated with electro-shock (54). Sedation by propofol in the treatment of intracranial hypertension caused by fulminant hepatic failure improves survival of these patients (55).

\subsubsection{Benzodiazepines (midazolam)}

Benzodiazepines as anti-anxiety, sedative, amnestic, hypnotic, anticonvulsant and muscle relaxant drugs are widely used. However, these drugs have no analgesic effect. Midazolam is a suitable alternative to diazepam in induction of anesthesia, especially in elderly patients, because of higher strength and shorter duration of action and also less cardiorespiratory depression (56). Midazolam accumulates in adipose tissue outside the CNS resulting in fewer CNS adverse effects. Midazolam adverse effects are like other benzodiazepines including a slight increase in heart rate and a slight decrease in systolic blood pressure that is aggravated in hypovolemic condition. Respiratory depression is an adverse effect of the medication, especially in cases of high doses 
and high-speed injection. In contrast to diazepam and chlordiazepoxide that increase hepatic metabolism, oxazepam and lorazepam glucoronized without hepatic metabolism are preferred (57). Park explained an acute liver failure due to the use of diazepam; it has been successfully treated in cats (58). Taking oral combination of lorazepam and tramadol before hepatic biopsy clearly reduces pain caused by biopsy (59).

\subsubsection{Opioids (Fentanyl)}

Fentanyl is a synthetic opioid used widely since 1968. The pharmacological effects of the drug include rapid clearance, high strength and less histamine release (60). Fentanyl passes blood-brain barrier rapidly, creates an analgesic effect in less than two minutes and quickly reduces serum levels of the drug in the body. The use of fentanyl causes less nausea and hypotension than other opioids (61). It causes muscle rigidity of the chest wall and diaphragm; the effect is more significant in cases of doses higher than 15 micrograms per kilogram of body weight and rapid injection of the drug (62). Another complication of fentanyl is respiratory depression, which is aggravated when used along with other CNS depressant drugs (63)

According to Zhao and Shen, remifentanil prevents liver damage due to ischemia by reducing apoptosis (64). Fentanyl, sufentanil and remifentanil are anesthesia drugs of choice in patients with liver failure. Due to decreased hepatic blood flow, metabolism of morphine and meperidine in patients with liver dysfunction and portal hypertension is greatly decreased, and fentanyl and sufentanil are preferred over these two drugs (8).

\section{Discussion}

Anesthesia in patients with cirrhosis and liver disorders is a challenging issue doubled by the use of systemic intravenous drugs. Many drugs used in anesthesia have hepatic metabolism, thus the use of these drugs in patients with impaired liver function should be cautious and anesthesiologist must be aware of metabolism pathway and adverse effects of anesthetic drugs to choose the best and the safest drug for these patients. Opioids are successfully used in patients with liver diseases and Fentanyl is the drug of choice for these patients. As the average dosage of drug is used, oxygen content of the liver and liver blood flow is not affected $(14,16)$. Among the drugs used for induction of anesthesia, propofol is the drug of choice in patients with liver diseases (17). As a rule, any type of long-acting local anesthetic in patients with cirrhosis should be avoided. Fentanyl from narcotics, lorazepam and oxazepam from sedatives along with some volatile anesthetic agent such as Sevoflurane or intravenous anesthetics such as propofol, are recommended in these patients (18-20).

\section{Authors' Contributions}

Study concept and design: Seyed Moayed Alavian and Hassan Soleimanpour; Drafting of the manuscript: Saeid Safari, Farzad Rahmani and Asghar Jafari Rouhi.

\section{References}

1. Mushlin PS, Gelman S. Anesthesia and the Liver. 4 edPhila $\neg$ delphia: Clinical Anesthesia; 2011.

2. Jones AL. Anatomy of the normal liver:Philadelphia: Saunders; 1996

3. Hanje AJ, Patel T. Preoperative evaluation of patients with liver disease. Nat Clin Pract Gastroenterol Hepatol. 2007;4(5):266-76.

4. Imani F, Motavaf M, Safari S, Alavian SM. The therapeutic use of analgesics in patients with liver cirrhosis: a literature review and evidence-based recommendations. Hepat Mon. 2014;14(10).

5. Habibollahi P, Mahboobi N, Esmaeili S, Safari S, Dabbagh A, Alavian SM. Halothane-induced hepatitis: A forgotten issue in developing countries: Halothane-induced hepatitis. Hepat Mon 2011;11(1):3-6.

6. Friedman LS. Surgery in the patient with liver disease. Trans Am Clin Climatol Assoc. 2010;121:192-204.

7. Rahimzadeh P, Safari S, Faiz SH, Alavian SM. Anesthesia for patients with liver disease. Hepat Mon. 2014;14(7).

8. Strunin L. Anesthetic management of patients with liver disease.London: Saunders; 1992.

9. Friedman LS. The risk of surgery in patients with liver disease. Hepatology. 1999;29(6):1617-23.

10. Klemperer JD, Ko W, Krieger KH, Connolly M, Rosengart TK, Altorki NK, et al. Cardiac operations in patients with cirrhosis. Ann Thorac Surg. 1998;65(1):85-7.

11. Pratt DS, Kaplan MM. Evaluation of abnormal liver-enzyme results in asymptomatic patients. N Engl J Med. 2000;342(17):126671.

12. De Wolf AM. 6/2/06 Perioperative assessment of the cardiovascular system in ESLD and transplantation. Int Anesthesiol Clin. 2006;44(4):59-78.

13. Behrns KE, Tsiotos GG, DeSouza NF, Krishna MK, Ludwig J, Nagorney DM. Hepatic steatosis as a potential risk factor for major hepatic resection. J Gastrointest Surg. 1998;2(3):292-8.

14. Hoetzel A, Ryan H, Schmidt R. Anesthetic considerations for the patient with liver disease. Curr Opin Anaesthesiol. 2012;25(3):3407.

15. Lautt WW. The 1995 Ciba-Geigy Award Lecture. Intrinsic regulation of hepatic blood flow. Can J Physiol Pharmacol.1996;74(3):22333.

16. Kiamanesh D, Rumley J, Moitra VK. Monitoring and managing hepatic disease in anaesthesia. BrJ Anaesth. 2013;111 Suppl 1:i5061.

17. Vaja R, McNicol L, Sisley I. Anaesthesia for patients with liver disease. (CEACCP). 2009;10(1):15-9.

18. Kurosawa M, Unno T, Aikawa Y, Yoneda M. Neural regulation of hepatic blood flow in rats: an in vivo study. Neurosci Lett. 2002;321(3):145-8.

19. Keegan MT, Plevak DJ. Preoperative assessment of the patient with liver disease. Am J Gastroenterol. 2005;100(9):2116-27.

20. Schwartz RB, Shepherd G. Pharmacologic Adjuncts to Intubation. 6 ed: Elsevier; 2014.

21. Harvey SC. Hypnotics and sedatives.New York: Macmillan; 1985.

22. Dripps RD, EckenhoffJE, Vandam LD. Intravenous anesthetics. 7 edPhiladelphia: Saunders; 1988.

23. Bedford RF, Persing JA, Pobereskin L, Butler A. Lidocaine or thiopental for rapid control of intracranial hypertension? Anesth Analg. 1980;59(6):435-7.

24. Shapiro HM, Wyte SR, Loeser J. Barbiturate-augmented hypothermia for reduction of persistent intracranial hypertension. J Neu rosurg. 1974;40(1):90-100.

25. Sivilotti ML, Ducharme J. Randomized, double-blind study on sedatives and hemodynamics during rapid-sequence intubation in the emergency department: The SHRED Study. Ann Emerg Med. 1998;31(3):313-24.

26. Pandele G, Chaux F, Salvadori C, Farinotti M, Duvaldestin P. Thio- 
pental pharmacokinetics in patients with cirrhosis. Anesthesiology. 1983;59(2):123-6.

27. North Chicago, IL: 1993. Pentothal thiopental sodium for injection prescribing information.

28. Thiopental Sodium for injection prescribing information. 1998 Deerfield, IL:

29. Hasselstrom L, Kristoffersen MB. Hepatitis following thiopentone. A case report. Br J Anaesth.1979;51(8):801-4.

30. Levron JC, Assoune P. [Pharmacokinetics of etomidate]. Ann Fr Anesth Reanim. 1990;9(2):123-6.

31. Pouraghaei M, Moharamzadeh P, Soleimanpour H, Rahmani F, Safari S, Mahmoodpoor A, et al. Comparison between the effects of alfentanil, fentanyl and sufentanil on hemodynamic indices during rapid sequence intubation in the emergency department. Anesth Pain Med. 2014;4(1).

32. Gooding JM, Weng JT, Smith RA, Berninger GT, Kirby RR. Cardiovascular and pulmonary responses following etomidate induction of anesthesia in patients with demonstrated cardiac disease. Anesth Analg. 1979;58(1):40-1.

33. Bergen JM, Smith DC. A review of etomidate for rapid sequence intubation in the emergency department. J Emerg Med. 1997;15(2):221-30.

34. Smith DC, Bergen JM, Smithline H, Kirschner R. A trial of etomidate for rapid sequence intubation in the emergency department. J Emerg Med. 2000;18(1):13-6.

35. Wadbrook PS. Advances in airway pharmacology. Emerging trends and evolving controversy. Emerg Med Clin North Am. 2000;18(4):767-88.

36. Famewo CE. The safety of etomidate: a new intravenous anaesthetic induction agent. Afr J Med Med Sci.1983;12(2):95-9.

37. van Beem H, Manger FW, van Boxtel C, van Bentem N. Etomidate anaesthesia in patients with cirrhosis of the liver: pharmacokinetic data. Anaesthesia. 1983;38 Suppl:61-2.

38. Wong GL, Tam YH, Ng CF, Chan AW, Choi PC, Chu WC, et al. Liver injury is common among chronic abusers of ketamine. Clin Gastroenterol Hepatol. 2014;12(10):1759-62 e1.

39. Zhou J, Shaw SG, Gilleece Y. Dilated common bile duct and deranged liver function tests associated with ketamine use in two HIV-positive MSM. Int J STD AIDS. 2013;24(8):667-9.

40. Gutkin E, Hussain SA, Kim SH. Ketamine-induced biliary dilatation: from Hong Kong to New York. J Addict Med. 2012;6(1):89-91.

41. Noppers IM, Niesters M, Aarts LP, Bauer MC, Drewes AM, Dahan A, et al. Drug-induced liver injury following a repeated course of ketamine treatment for chronic pain in CRPS type 1 patients: a report of 3 cases. Pain. 2011;152(9):2173-8.

42. Khajavi M, Emami A, Etezadi F, Safari S, Sharifi A, Shariat Moharari R. Conscious Sedation and Analgesia in Colonoscopy: Ketamine/ Propofol Combination has Superior Patient Satisfaction Versus Fentanyl/Propofol. Anesth Pain Med.2013;3(1):208-13.

43. Swanson ER, Seaberg DC, Mathias S. The use of propofol for sedation in the emergency department. Acad Emerg Med. 1996;3(3):234-8.

44. Burton JH, Miner JR, Shipley ER, Strout TD, Becker C, Thode HI. Propofol for emergency department procedural sedation and analgesia: a tale of three centers. Acad Emerg Med. 2006;13(1):2430.

45. Langley MS, Heel RC. Propofol. A review of its pharmacodynamic and pharmacokinetic properties and use as an intravenous anaesthetic. Drugs. 1988;35(4):334-72.
46. Rison RA, Ko DY. Isolated fatty liver from prolonged propofol use in a pediatric patient with refractory status epilepticus. Clin Neurol Neurosurg. 2009;111(6):558-61.

47. Soleimanpour H, Ghafouri RR, Taheraghdam A, Aghamohammadi D, Negargar S, Golzari SE, et al. Effectiveness of intravenous dexamethasone versus propofol for pain relief in the migraine headache: a prospective double blind randomized clinical trial. BMC Neurol. 2012;12:114.

48. Soleimanpour H, Taheraghdam A, Ghafouri RR, Taghizadieh A, Marjany K, Soleimanpour M. Improvement of refractory migraine headache by propofol: case series. Int J Emerg Med. 2012;5(1):19.

49. Laquay N, Prieur S, Greff B, Meyer P, Orliaguet G. [Propofol infusion syndrome]. Ann Fr Anesth Reanim. 2010;29(5):377-86.

50. Fodale V, La Monaca E. Propofol infusion syndrome: an overview of a perplexing disease. Drug Saf. 2008;31(4):293-303.

51. Faga E, De Cento M, Giordanino C, Barletti C, Bruno M, Carucci $\mathrm{P}$, et al. Safety of propofol in cirrhotic patients undergoing colonoscopy and endoscopic retrograde cholangiography: results of a prospective controlled study. Eur J Gastroenterol Hepatol. 2012;24(1):70-6.

52. Amorós A, Aparicio JR, Garmendia M, Casellas JA, Martínez J, Jover R. Deep sedation with propofol does not precipitate hepatic encephalopathy during elective upper endoscopy. Gastrointest Endosc. 2009;70(2):262-8.

53. Bamji N, Cohen LB. Endoscopic sedation of patients with chronic liver disease. Clin Liver Dis. 2010;14(2):185-94.

54. Asai A, Yagi M, Tsuchimoto Y, Fukunishi S, Takeshita A, Tsuda Y, et al. A rare case of propofol-induced liver injury during modified electroconvulsive therapy in an elderly woman. Intern Med. 2013;52(7):761-5.

55. Raghavan M, Marik PE. Therapy of intracranial hypertension in patients with fulminant hepatic failure. Neurocrit Care. 2006;4(2):179-89.

56. Whitwam JG, Al-Khudhairi D, McCloy RF. Comparison of midazolam and diazepam in doses of comparable potency during gastroscopy. BrJ Anaesth.1983;55(8):773-7.

57. Friedman LS, Maddrey WC. Surgery in the patient with liver disease. Med Clin North Am. 1987;71(3):453-76.

58. Park FM. Successful treatment of hepatic failure secondary to diazepam administration in a cat.J Feline Med Surg. 2012;14(2):158-60.

59. Kramskay R, Tansky A, Eisenberg E, Veitsman E, Baruch Y. Prophylactic analgesia before percutaneous liver biopsy: a clinical comparative study. Eur J Gastroenterol Hepatol. 2011;23(9):782-6.

60. Mostert JW, Trudnowski RJ, Seniff AM, Moore RH, Case RW. Clinical comparison of fentanyl with meperidine. J Clin Pharmacol J New Drugs.1968;8(6):382-91.

61. Schleimer R, Benjamini E, Eisele J, Henderson G. Pharmacokinetics of fentanyl as determined by radioimmunoassay. Clin Pharmacol Ther.1978;23(2):188-94.

62. Comstock MK, Carter JG, Moyers JR, Stevens WC. Rigidity and hypercarbia associated with high dose fentanyl induction of anesthesia. Anesth Analg.1981;60(5):362-3.

63. Chudnofsky CR, Wright SW, Dronen SC, Borron S, Wright MB. The safety of fentanyl use in the emergency department. Ann Emerg Med.1989;18(6):635-9.

64. Zhao G, Shen X, Nan H, Yan L, Zhao H, Yu J, et al. Remifentanil protects liver against ischemia/reperfusion injury through activation of anti-apoptotic pathways. J Surg Res. 2013;183(2):827-34. 